\title{
CORONTA DE MANZANA: SIGNO EN RADIOLOGIA GASTROINTESTINAL
}

\section{Dr. Claudio Cortés A}

Universidad de Chile. Universidad del Desarrollo.

\section{THE APPLE CORE: GASTROINTESTINAL RADIOLOGY SIGN}

\section{Aspecto imaginológico}

El signo de la coronta de manzana, corresponde a la pérdida de calibre circunferencial de un segmento breve del colon, que se inicia en forma abrupta, con irregularidad y asimetría del relieve mucoso en el segmento estrechado y que también termina en forma abrupta, recuperando el colon su calibre y relieve mucoso. Los extremos de la lesión se denominan hombros y generalmente protruyen en el lumen.

\section{Reseña histórica}

El hallazgo de un estrechamiento abrupto circunferencial, indicativo de un cáncer de colon, es reconocido y reportado como típico desde las primeras enemas opacas utilizadas como método de diagnóstico con rayos $X$. Fue reportado por Schule en $1904^{(1)}$, cuando el contraste empleado era el subnitrato de bismuto, usado para el tratamiento de úlceras gástricas desde 1890. Rumpel, el 20 de abril de 1897 fue el primero en reportar radiografías de un segmento del tubo digestivo opacificado por solución de bismuto, hallazgo incidental ${ }^{(2)}$.

El estrechamiento circunferencial se denominó "anillo de servilleta" (napkin ring) y al caer este utensilio en desuso en nuestra sociedad de creciente afición a la comida rápida, se acuñó el término "coronta de manzana" (apple core) (Figura 1).

\section{Significado}

Indica la presencia de una lesión que engruesa la pared del colon, en toda la circunferencia del segmento comprometido, y por ello aparece menos distensible que los segmentos intestinales que la

Cortés C. Coronta de manzana: Signo en radiología gastrointestinal. Rev Chil Radiol 2009; 15(2): 92-94.

Correspondencia: Dr. Claudio Cortés $A$.

claudiocort@gmail.com

Trabajo recibido el 03 de mayo de 2009, aceptado para publicación el 25 de mayo 2009.

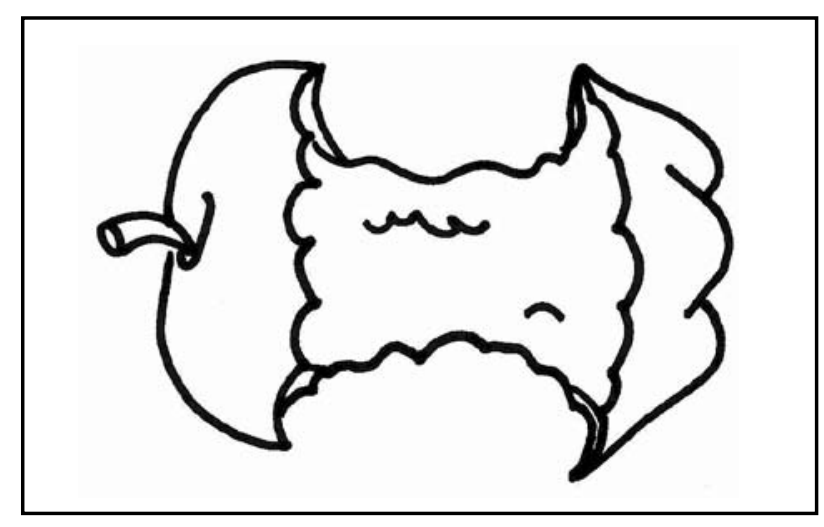

Figura 1. Coronta de manzana.

preceden y la suceden. Generalmente su longitud es breve, entre tres y cuatro centímetros en el eje longitudinal del colon y raramente excede los seis centímetros ${ }^{(3)}$.

La coronta de manzana corresponde mayoritariamente a un adenocarcinoma anular, en estadio avanzado.

\section{Diagnóstico diferencial}

No es una imagen específica ni patognomónica; en su diagnóstico diferencial debe considerarse:

1. Lesiones inflamatorias benignas:

- Diverticulitis: el segmento estrecho suele ser más largo, el engrosamiento mural es menor y hay divertículos visibles.

- Enfermedad de Crohn del colon: el comienzo y término generalmente son graduales y no abruptos.

2. Isquemia:

- Segmento estrecho y más largo que en el adenocarcinoma

3. Secuelas de radioterapia:

- Existencia de antecedentes clínicos.

4. Infecciones: infrecuentes en nuestro país

- TBC, en el área ileocecal

- Clamidia

- Linfogranuloma venéreo, en recto. 


\section{Lesiones malignas}

- Linfomas, habitualmente presentan segmentos comprometidos más largos y menos estrechos, por poca reacción desmoplástica.

- Metástasis: en estos casos, el tumor primario más frecuente, pero no el único, es la neoplasia de estómago, vía epiplón gastrocólico o por contigüidad.

\section{Discusión}

La imagen que semeja una manzana parcialmente comida en forma circunferencial es frecuente y puede corresponder a un adenocarcinoma anular del colon. Aunque se acuñó el término en enemas baritadas simples, siguió siendo útil en enemas de doble contraste (Figura 2) y continúa vigente en topogramas (Figura 3), en tomografías computadas (Figura 4), en colonoscopías virtuales por tomografía computada (Figura 5) y en resonancia magnética (Figura 6).
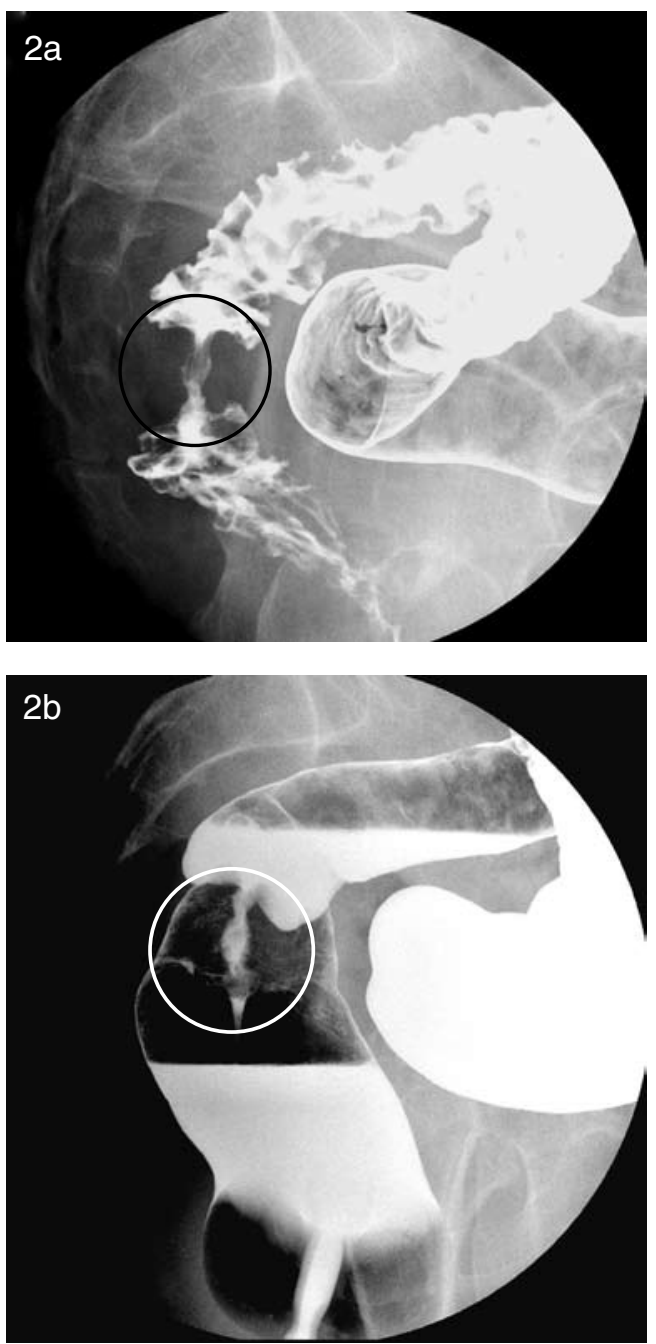

Figura 2. Signo de coronta de manzana en enemas baritadas: simple (a) y doble contraste (b).

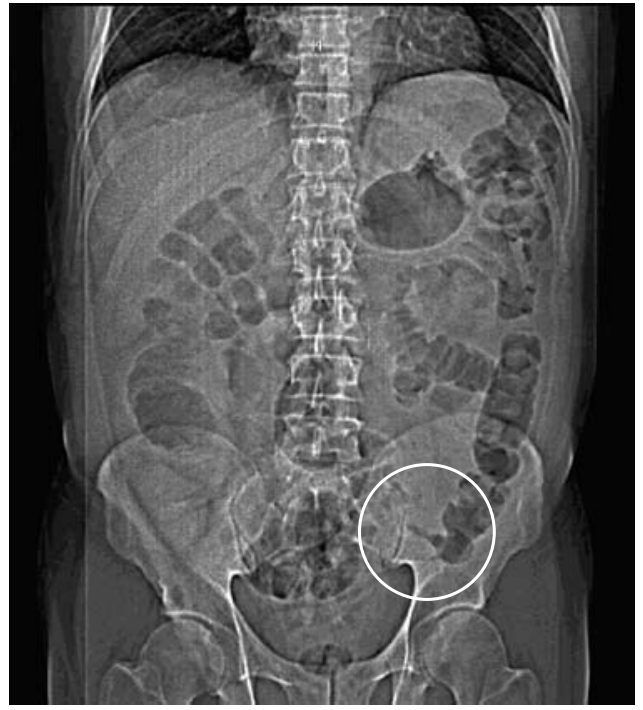

Figura 3. Signo de coronta de manzana en topograma de tomografía computada.
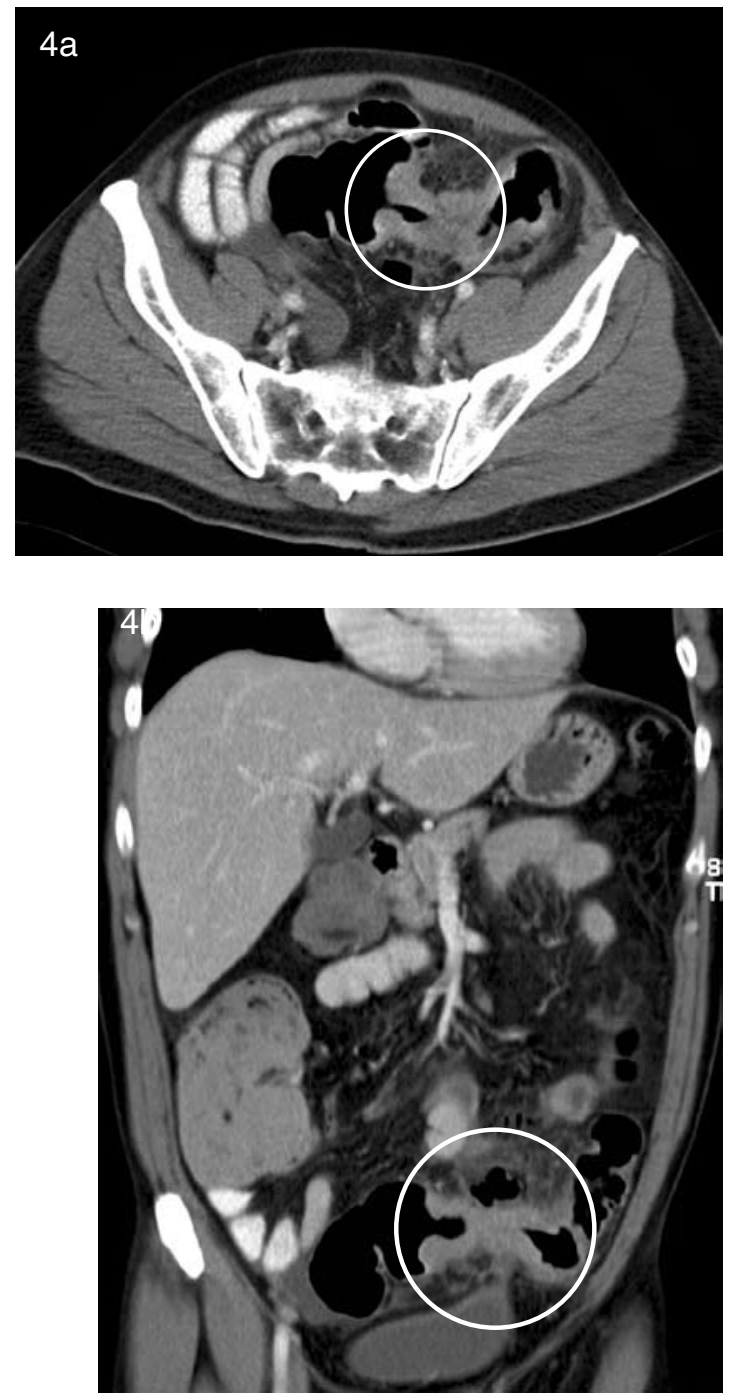

Figura 4. Signo de coronta de manzana en tomografía computada: a) corte axial. b) reconstrucción coronal. 

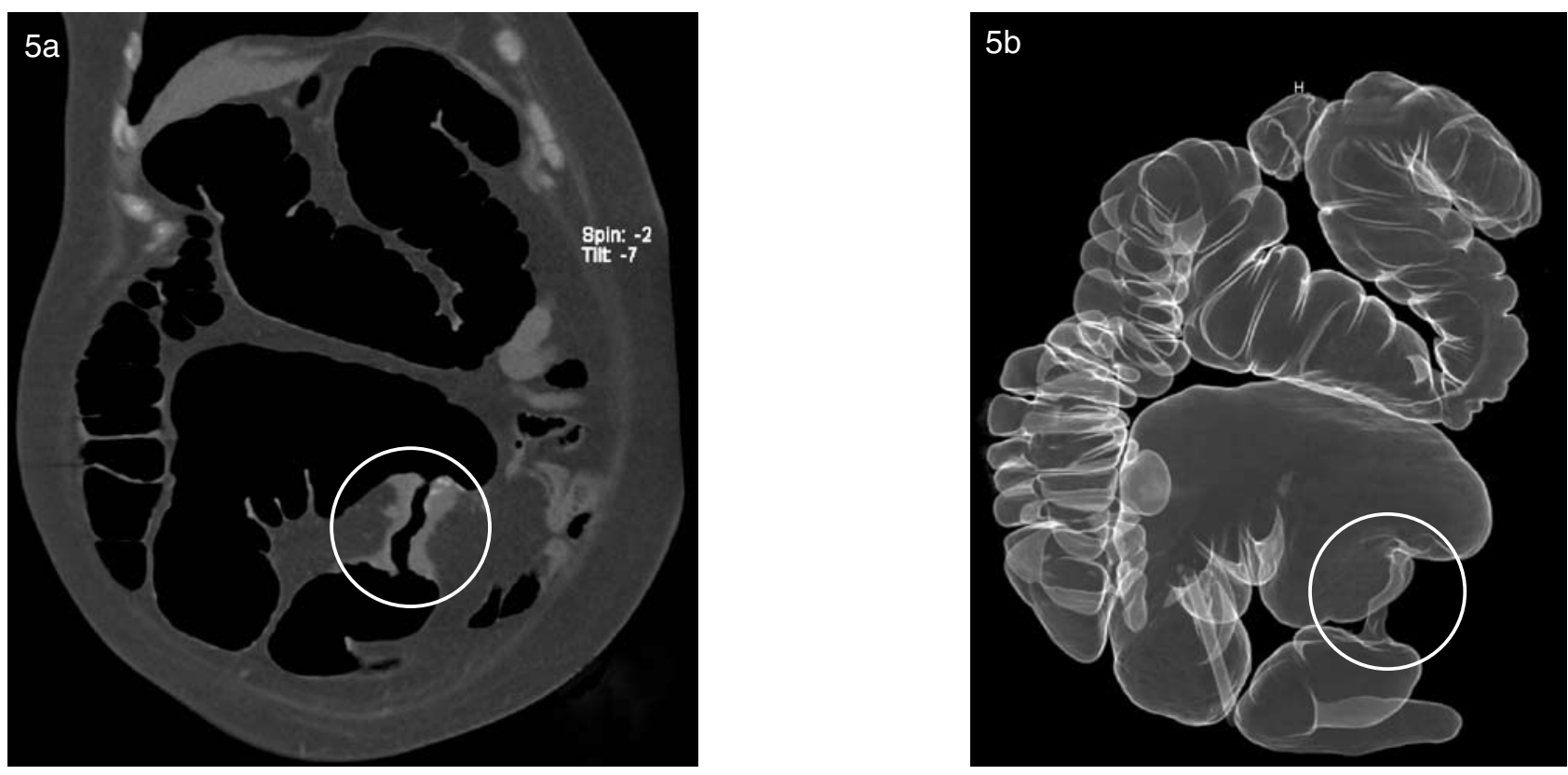

Figura 5. Signo de coronta de manzana en colonoscopía virtual por tomografía computada: a) coronal . b) reconstrucción volumétrica.

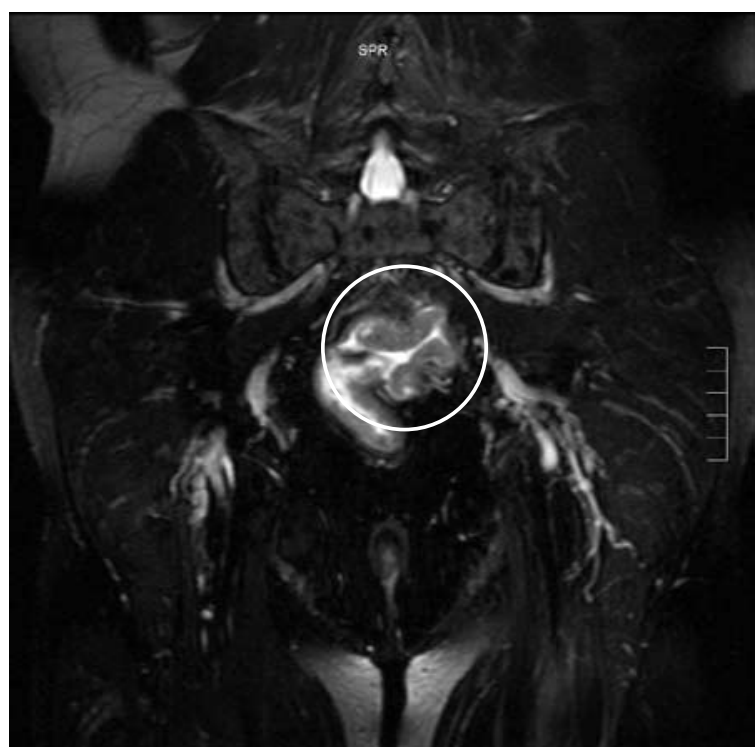

Figura 6. Signo de coronta de manzana en resonancia magnética, corte coronal en secuencia.

Algunos signos se repiten en imaginología y es así como coronta de manzana también es un signo importante en radiología osteoarticular ${ }^{(4)}$. Así sucede también con otros signos en imágenes del tubo digestivo: el signo del "pico pájaro" se puede observar en el extremo caudal de un esófago con acalasia y también en el punto de torsión de un vólvulo sigmoideo.

\section{Comentario}

Damos la partida a un nuevo segmento de nuestra Revista con este signo radiológico clásico y tradicional, que nació en los albores de la radiología cuando sólo existía el tubo de rayos $\mathrm{X}$ y que sigue muy vigente hoy día en la variada tecnología actual. Porque el cáncer de colon crece en frecuencia, los radiólogos de cuerpo y muy especialmente los de tubo digestivo, tenemos presente este signo cada día en nuestros hospitales y clínicas ${ }^{(5,6)}$.

Invito en nombre de la Dra. Karla Moënne, Editora de la Revista Chilena de Radiología, y de todo el Comité Editorial, a los residentes de los programas de formación de radiología y a los colegas radiólogos a aportar signos radiológicos de las diferentes áreas de la nuestra especialidad.

\section{Bibliografía}

1. Schule A. Intubation and radiography of the large intestine. Arch Verdauungskd Staffwechselpathol Diat 1904; 10: 111-118.

2. Rumpel $\mathrm{T}$. The clinical diagnosis of fusiform dilatation of the esophagus. Muenchen Med Wschr 1897; 44: 420-421.

3. Simpkins CC, Young AC. The differential diagnosis of large bowel strictures. Clin Radiol 1971; 22: 449457.

4. Freyschmidt J. The apple core sign. Eur Radiol 2002; 12: 245-247.

5. Dahnert W. Radiology Review Manual 3rd ed. Baltimore, Md: Williams \& Wilkins, 1996.

6. Eisenberg R. L (1992) Radiology An llustrated History p 278. St Louis: Mosby-Year Book Inc. 